\title{
Movie Titles' E-C Translation from the Perspective of Domestication and Foreignization
}

\author{
Dongxu Mai \\ Department of Performance \\ Shenzhen University \\ Guangdong, China
}

\begin{abstract}
Today, Hollywood movies have been very popular in the Chinese movie market. Therefore, the translation of English movies has become crucial. Especially, the translation of movie titles is the first impression of a movie to the audience. Only in a good grasp on the meaning of English and Chinese semantics, meanwhile considering artistically and commercially, can a good movie title be well translated. This thesis mainly discusses the translation of English movie titles from the perspective of domestication and foreignization. In the first part, the thesis concludes the current situation of the translation of movie titles in China and some criteria of movie title translating. In the second part, the thesis will introduce the concept of domestication and foreignization and specify domestication strategies and foreignization strategies and their application in movie title translating. Moreover, factors that influence the choice of two strategies while translating movie titles are discussed as well. Finally, the relationship between domestication and foreignization are discussed and analyzed. A conclusion can be drawn: they are in a dialectical and uniform relationship. The translator should combine domestication with foreignization in regard to various contexts.
\end{abstract}

Keywords-movie titles; translation; domestication; foreignization

\section{INTRODUCTION}

With the development of economic globalization, the movie market develops tremendous. Meanwhile, movie market has become a part of the economic growth that cannot be ignored. The translation of movie titles is essential for the movie market. English movie titles should be translated into Chinese when they enter Chinese movie market. Therefore, domestication and foreignization play a key role in the translation of movie titles.

Domestication or foreignization, which is more important? The problem is a focus of the translation. The famous American translation theorist Lawrence Venuti came up with this discussion in his book-Translators' invisibility, however, Lawrence Venuti's work is primarily for literature and he also pointed out: Different kinds of texts should be translated in different methods. This thesis puts these methods into another special texts-the translation of movie titles.

Nowadays, more and more movie titles are translated and the translation of movie titles as the key for the movie has been successfully achieved in foreign markets. A good translation of the movie title can not only faithfully convey the theme of the movie, but also can generate lucrative business income, and even reflect a certain aesthetic value, providing a person with enjoyable experience.

Because movie is the carrier of culture, the cultural factors also will be reflected in the movie title. The translation of movie titles seems to be easy, but it is difficult to translate refined and compatible movie titles.

Domestication and foreignization as two kinds of strategies are great significance to the translation of movie titles. How could they be applied properly in the translation of movie titles? And what are the influential factors of the choice of two strategies? These problems will be discussed in this thesis.

The object of this study focuses mainly on the Oscar movies. They are discussed mainly by methods of theoretical analysis and contrasting.

\section{LITERATURE REVIEW OF DOMESTICATION AND FOREIGNIZATION}

The German translation theorist Schleietmacher pointed out in his speech that there are two kinds of ways to translate - the translator leaves the author in peace and moves the reader towards the author; or the translator leaves the reader in peace, as much as possible, and moves the author towards the reader. The first method is foreignization and the second method is domestication.

The American translation theorist Lawrence Venuti was inspired by Schleietmacher and put forward two kinds of strategies of translation in his book, Translators' invisibility - domestication and foreignization. Dictionary of Translation Studies published by the British St Jerome press, pointed out that domestication refers to the translation strategy in which a transparent and fluent style is adopted to minimize the strangeness of the foreign text for the target readers. Foreignization is retaining the foreignness of original translation, breaking translation of normal sense.

In China, there is also concept of the same meaning. In the 20th century 20s or $30 \mathrm{~s}$, Mr. LuXun (a famous Chinese writer) pointed out the problem about domestication and foreignization during the disputation of literal translation or 
liberal translation. Mr. LuXun stated: "Before you begin, firstly you have to solve a problem: are you trying to make it domesticating, or make it foreignizating" [1].

\section{A. The Concept of Domestication and Foreignization}

Accordingto Schuttleworth and Cowie, domestication refers to a term used by Venuti to describe the translation strategy in which a transparent, fluent style is adopted in order to minimize the strangeness of the foreign text for target language readers [2]. On the same basis as the previous one, foreignization refers to a term used by Venuti to designate the type of translation in which a target text is produced which deliberately breaks target conventions by retaining something of foreignness of the original [3].

Take the movie lines from the movie Casablanca as an example: "The drive back to my home in Edmoonton was an endless journey of destructive emotions and thoughts. In a truck-stop restaurant, I sat staring at a glass of cheap red wine. Of all the gin joints in all the towns in all the world, she walks out of mine" [4].

We can translate it in the method of domestication: “在我 开车回到埃德蒙顿的路上, 我陷入了无尽的悲伤之中。随后，我来到 一家汽车旅馆, 端着一杯廉价红酒出神, 觉着这世上有那么多家旅 馆, 她终究还是走出了我的那一家” [5]. (Means The drive back to my home in Edmoonton ... wine. Of all the gin joints in all the towns in all the world, she walks out of mine)

We can translate it in the method of foreignization: “在我 开车回到埃德蒙顿的路上, 我陷入了无尽的悲伤之中。随后, 我来到 一家汽车旅馆, 端着一杯廉价红酒出神, 弱水三千, 终究我已不是她 那瓢中的一壶水了”[6]. (means The drive back to my home in Edmoonton ... wine. You are the only one for me in my world but I'm not in your)

\section{B. The Study of Domestication Strategies and Foreignization Strategies}

Domestication has been one fundamental strategy in dealing with the cultural factors in the process of translating, with its opposite as foreignization. According to Dictionary of Translation Studies published in England 1997,domestication and foreignization, the two terminologies are the terms coined by Lawrence Venuti in 1995, directly originated from the German thinker Schleiermacher's speech On the Different Methods of Translating in 1813.Domestication means making the text recognizable and familiar and thus bringing the foreign culture closer to the reader in the target culture while foreignization designates the type of translation in which a target text "deliberately breaks target conventions by retaining something of the foreignness of the original"[7].

The root of these two terms can be traced back to the German philosopher Schleiermacher's speech in 1813. He said that there are only two different methods of translation, "either the translator leaves the author in peace, as much as possible, and moves the reader towards him; or he leaves the reader in peace, as much as possible, and moves the author towards him" [8]. The former only refers to foreignization, while the latter refers to domestication. In the translation practice, the two strategies are both alternatives to a translator. "For example, as to the translation of some culture-bound words in the source text, a translator may consider whether he should be close to the source culture or the target culture and to what extent.

\section{THE APPLICATION OF DOMESTICATION AND FOREIGNIZATION TO THE TRANSLATION ON ENGLISH MOVIE TITLES IN CHINA}

Movie has been born in France since 1895.That's a history of more than 100 years. In 1905, China produced the first movie and in the early 20th century there was a precedent of foreign movie's introduction. In the end of the 20th century, after the reform and opening-up policy, Chinese movie market is more and more open and inclusive, which makes an increasing number of foreign movies to be officially released in China. And among these movies, they were represented by Hollywood movies, with English movies occupying the majority of foreign movies.

Although a large number of foreign movies were introduced into Chinese movie market, truly correct and appropriate translation of movie titles could hardly be found. And non-standard translation is a common fact. The phenomenon of disunified and disordered translation also results in confusion of movie market. It is not hard to notice that without the translation of movie titles; hardly can individuals be clear about the approximate information of foreign movies. Business organizations focus merely on making money, let alone obtaining wealth in the long term, especially in fiercely competitive movie market. That will be a sorry state of affairs. The translation of movie titles mainly includes the following three problems.

\section{A. The Problem of the Translation on English Movie Titles in China}

1) Different translation in different regions: According to current documents, there is something different between mainland China and Hongkong and Taiwan. For example, the $84^{\text {th }}$ Oscar movie, King's Speech was translated into 《国 王的演讲》(means a king's speech) by movie company of mainland, the one of HongKong was《皇上无话讲》(means a king can't do speech), and the one of Taiwan was《王者之 声》 (means king'voice). The $88^{\text {th }}$ Oscar movie, The Revenant was translated into 《荒野猎人》(means the wild hunter)by mainland, the one of HongKong was 《复仇勇者》 (means revengeful warrior), and the one of Taiwan was 《神 鬼猎人》 (means the ghost hunter). The $89^{\text {th }}$ Oscar movie, Hacksaw Bidge was translated into 《血战钢锯岭》 by mainland(means tragic war in hacksaw), the one of HongKong was 《钢锯岭》(means hacksaw), the one of Taiwan was 《钢铁英雄》(means iron hero).

It is because of social and historical reasons so that different regional cultures between mainland China and HongKong and Taiwan emerged are different. Therefore, the same movie title for translation does become three different versions in Chinese movie market.

According to the regulation of China's State Administration of Radio, Film and Television, there are 38 
English movies, being introduced in the form of authority in 2016, that is to say, Chinese movie market has 38 English movie titles should be translated in the form of authority in this year. At the same time, a lot of English movies are pouring into HongKong and Taiwan markets. Those English movies introduced by HongKong or Taiwan would also enter the mainland China market in the unofficially form of DVD. Although these English movies are the same to those which were introduced officially by mainland China, movie titles which came from Hong Kong and Taiwan, led to the confusion of movie market in the region--mainland China.

2) The confused translation caused by media: Media goes on their own ways without unified and coordinated management and fail to pay attention to use standard translation, which fuel the the situation of chaos. In order to occupy a commanding height of headlines, some entertainment media are inclined to translate movie titles respectively. For example, the movie title--Trueman Show has five versions: 《特鲁门节目》(means trueman's program), 《特鲁门时间》(means trueman's time), 《真人显示》(means real person's displaying), 《真人活剧》(means real person drama)and《楚门的世界》(means the world of trueman). In addition, the development of the internet is also a common barrier for the standardization of the translation of movie titles. A number of non-professional netizens or entertainment websites enjoy translating movie titles respectively, uploading titles to websites, in order to provide netizens with downloading.Nowadays, the trend that movies are downloaded from the internet has become a common phenomenon. However, different translation versions uploaded by various kinds of BBS will lead to chaotic situation.

3) Carelessand intemperate translation: The quality of the translation of movie titles is another serious problem besides of the chaotic situation out of the variety of versions. It is the main reason for the phenomenon of careless and intemperate translation that some film distributors pursue exparte commercial profit. They tend to make movie titles attractive. For example, Arnold Schwarzenegger was famous for The Terminator all over the world, becoming one of the most popular action stars. The title of the movie was translated into《魔鬼终结者》 (means terminator of devil)by HongKong. After that, various kinds of movies played by Arnold were translated with "devil" in order to get even more his fans into the cinema, such as Running Man-《魔鬼阿诺》(means Arnold is devil ), True Lies-《魔鬼 大帝》(means king of devil ), Kindergarten Cop--《魔鬼孩子 王》(means king of demoniac kid ), Total Recall-- 《魔鬼总动 员》(means general mobilization of devil). It is ludicrous, however, that some of movies above are comedy movies, being translated with “魔鬼” (devil)--two Chinese words universally regarded horrible. Using Arnold Schwarzenegger' symbolic name--“魔鬼” (devil) in the translation of movie title to attract fans, movie distributors obtain a huge sum of money, meanwhile they also destroy the accuracy of the translation rather than translating movie titles aritsitcally.

\section{B. Principles of the Translation on English Movie Titles - Artistry and Commerciality}

With the social progress and the development of academy, there are various standards of translation. To some degree, the translation of movie titles as a special work has its formal some standards. Among all the standards relating to translation that have been established the most impressive and important ones are artistry and commerciality.

1) Artistry and commerciality: Chinese famous Translator--YanFu argued in the end of the 19th century that there are three criterions in translation that are faithfulness, expressiveness and, elegance. "Elegance" refers to the elegance of translation. This means that translation requires artistry which could be applied to the translation of movie titles as well. On the other hand, movie is a kind of material product, circulating through a variety of mediaon the market and being commercial. This means that movies require commerciality, which can be applied to the translationof movie titles as well.

2) The relation of Artistry and Commerciality: Commerciality is expected to be seen as the purpose of artistry. Movie is not only an artistic work, but also a commodity, circulating on the market. If audience will not buy movie tickets, watching movies. The translation of movie titles will be meaningless, even if the translation of movie titles is elegant. For example, the 38th Oscar movie, The Sound of the Music was translated into《仙乐漂漂何处 闻》(means music from heaven floats where we can listen) by mainland China. As a matter of fact, these Chinese words “仙乐漂漂何处闻” derives from the famous Chinese Tang Dynasty poet, Bai Juyi's ChangHenGe (a Chinese ancient poetry).It is graceful and elegant that the movie was translated by this way, however without poetry knowledge of the Tang Dynasty, people could hardly to understand the translation of movie title meaning which barely has commercial value. Instead of being translated into《仙乐漂漂 何处闻》, using《音乐之声》(the one translated by HongKong and means the sound of music)as the movie title would be better.

Artistry is expected to be seen as the basis of Commerciality. Because of elegant and artistic quality, not only can movie titles satisfy the audience's psychology, but also will they attract the audience's attention, and even achieve its business value. That is, commerciality of movie titles is based on the artistic quality. Movie title is a trademark of a movie. Being the first impression of movie facing audience, if movie title is too vulgar and naive to be known and accepted on the market, it fails to catch the audience's eyeballs. For example, the 39th Oscar movie, Who's Afraid of Virginia Woolf (Virginia woolf, an English woman writer, is the forerunner of feminism.) was translated into《谁怕又贞又淫的女人》(means who is afraid of chaste and lascivious woman)by HongKong. This kind of translation fails to keep artistic so that people don't give priority to this 
movie title. Instead of being translated into《谁怕又贞又淫的女 人》, using 《灵欲春宵》(the one translated by mainland China and means soul and lust yearn for the deep of night) as the movie title, better yet, obtain more box office.

\section{The Practical Application of Domestication and Foreignization to the Translation on English Movie Titles}

1) The application of domestication: First, as the source culture and target culture may have completely different aesthetic preferences and linguistic traditions, the translator is required to bridge the differences to facilitate the communication by adopting the domestication strategy. When English movie titles are translated with Chinese culture, translators should take the factor that Chinese people are linguistically in the habit of using four-character phrases and the poetic style with five or seven characters in a single line. Such as these Oscar movies: Shakespeare in Love《莎翁情史》(means the love history of Shakespeare ), Speed 《生死时速》(means the speed of life and death), Catch Me If You Can《猫鼠游戏》(means the cat-and-mouse game), Scent of a Woman《闻香识女人》 (means knowing the woman by smelling the scent), Pocahoutas 《风中奇缘》 (means romance in wind), and so on. That will be more close to the Chinese culture and the people's life. This is a strategy of domestication.

Second, each culture is characterized by its unique fairy tales, legends and historical anecdotes. Take the 63th Oscar movie Ghost as an example. Ghost in China called《人鬼情未 了》(means the love of human and ghost is not over). The story just like a Chinese ancient love stories about human and spirit, Man and Fox. So this translation creates a kind of familiar feeling for Chinese audiences. This is a strategy of domestication. Moreover, Chinese characters “人” (human) and “鬼” (ghost) present a sharp contrast for Chinese audience, revealing that one of the couple is already dead. Besides, the three poetic words “情未了” (is not over) help create a sorrowful atmosphere that the couple is affectionately missing each other. As a result, the translated movie title was instantly accepted by Chinese audience and helped this movie turn out to be a sensation in 1990. Unique fairy tales, legends and historical anecdotes will be accepted easily by Chinese people.

Third, English movie titles are often created with names of people, but Chinese movie titles usually summarize the plot or utilize abstract words. For example the 67th Oscar movie, Forrest Gump. This story follows the life of low I.Q. Forrest Gump and his meeting with the love of his life, Jenny. Forrest Gumpis translated into 《阿甘正传》 (means autobiography of Gump)by China, which not only generalizes the story but also sounds quite natural in Chinese culture. “阿甘” (Gump) is a typical name and is always associated with a down-to-earth person. This title 《阿甘正传》 actually imitate from a novel autobiography of $\mathrm{Q}$ written by the famous Chinese writer Mr. LuXun. And Q is a man known by so many Chinese readers. So people would take interest in this movie since the translated title sounds familiar to Chinese audience. That is a strategy of domestication.

2) The application of Foreignization: First, foreignization translation believes in the aesthetic ability and receptivity of the audience and brings them directly to the exotic culture. It can be adopted to reflect cultural diversity and avoid the defect of cultural image and the disintegration of cultural content. According to foreignization theory, the version should be source language oriented or the original author oriented. Foreignization translation can give the target language audience the opportunity to know the exotic culture and appreciate the original flavor, which is one of the main purposes the audience seek for while appreciating the foreign movie. In addition, source language and culture can enrich the culture and the expressive way of target language. Therefore, translation can truly realize the function of intercultural communication through foreignization strategy.

Second, China has undergone dramatic changes since opening up to the outside world. Along with the rapid economic growth, China's international status has been greatly enhanced. Many westerners have shown strong interest in Chinese culture and want to get knowledge from it. The foreignization translation can meet their demands to contact Chinese culture. For example the 73th Oscar movie, 《卧虎藏龙》--Crouching Tiger, Hidden Dragon, the warmly received Chinese movie 《卧虎藏龙》 in the western world is directly translated into Crouching Tiger, Hidden Dragon. In Chinese culture, the undaunted and persistent image of the dragon becomes a symbol of national culture. Almost all the Chinese people like dragon and they regard themselves as descendants of the dragon. “卧虎藏龙” (crouching tiger, hidden dragon) these four Chinese words in Chinese actually refer to the undiscovered hidden talents. This is a kind of culture about dragon. This translation not only promotes the spread of the cultural connotation of Chinese dragon in the west, but also helps the westerners learn the Chinese language specialized in metaphors and implicit expressions.

Meanwhile, in western culture, the word "dragon" has totally different connotation. "Dragon" in Christianity is the image of devil. However, such a huge cultural contrast does not lead to misunderstanding. In fact, with the increasingly frequent intercultural communication, more and more westerners have begun to contact and understand Chinese culture. "Dragon", an image occupying a noble status in Chinese culture has also been gradually understood by the west.

Third, because of great differences in knowledge and cultural background between Chinese and foreigners, the translation of movie title should help the Chinese audience as far as possible to understand the linguistic phenomena that are closely related to the culture of English speaking countries. For example the 72th Oscar movie, American Beauty《美国丽人》(means American beautiful girl),this title is difficult to be understand for a vast majority of Chinese audience who have no experiences living in the United States. So the Chinese audiences would think why the beauty is so 
important in USA and who the American beauty is. In addition the Chinese another versions 《美丽有罪》(means beauty is guilty)cause easily confusion to the majority of Chinese audience. This version fails to convey the American culture tips reflected in the movie. American beauty is actually a kind of plant-American red roses, which appear in several scenes in the movie. The theme of the movie intends to criticize the declining middle class in the United States. Therefore, 《美国红蓄薇》(means American red rose), the direct foreignization of American Beauty is more appropriate. This version helps the Chinese audience to infiltrate into the foreign culture and establish the presupposition of the American culture so that the audience can understand its true aspect.

\section{Factors Influencing the Choice of the Two Strategies}

1) Cultural diversity: In order to achieve aims of translation, translators are supposed to proceed on the basis of different expected functions of movie titles, while seizing original movie titles intention and basing their work on the needs of audience, determining to keep up information of original movie titles or revise it according to the movie content. Especially, for those original movie titles which, will be dealt with difficultly due to cultural diversity. Translators are expected to consider carefully about the selection of domestication and foreignization strategies under the grasp of the target language audience's expectation field of vision and aesthetic orientation premise.

2) Audience's ability of accepting information: Adopting foreignization is to let the audience be faced with different culture signals, to expand their experience and horizons. And then adopting domestiction is to take audience's cognition into account, breaking original form of movie titles. "Sentence-oriented" principle-the method of sentence analysis from $\mathrm{Li}$ Jinxi could be available the combining the process of, grasping language and cultural diversity between original titles and the translation, while considering the social context and the audience's cultural habits, and choosing appropriate translation form of movie titles on different levels of grammar, vocabulary, semantics, rhetoric.

\section{CONCLUSION}

This paper mainly discussed from the perspective of domestication and foreignization the E-C translation of movie titles.First, current situation and problems of the movie titles translation in China were pointed out. Second,standards of the translation of movie titles were introduced.At last, the choice of two strategie-domestication and foreignization, were discussed in detail.

In a word, inpractice of the translation of movie titles, there is no domestication without some degree of foreignization, likewise, there is no foreignization without some degree of domestication. The two translation strategies co-exist and complement each other in the long term in the translation of English movie titles into Chinese.
If domestication was adopted blindly for the source language culture, although that will benefit the target language readers, information carried by the source language cultural will be lost so that it will exert negative influence on the intercultural communication and development. There is no doubt that this is translation cultural hegemonism. This kind of domestication believes the fact that original culture and artistic facts, cheat readers. With the fusion and development of world culture, an increasing number of the source language culture was understood by the target language users. They are no longer satisfied with the general ideas of translation known as domestication. So people will be inclined to accept foreignization to a further extent in the 21 st century.

\section{REFERENCES}

[1] Lu Xun.QieJieTing two essays.Luo Xinzhang.Essays on translation Beijing:The commercial press of Beijing.1984.

[2] Lawrence, Venuti. The Translator's Invisibility. London \& New York: Routledge, 1995.

[3] Lawrence, Venuti. The Translator's Invisibility. London \& New York Routledge, 1995.

[4] https://baike.baidu.com/item/\%E5\%BD\%92\%E5\%8C\%96\%E5\%BC $\% 82 \%$ E5\%8C\%96/2291724

[5] https://baike.baidu.com/item/\%E5\%BD\%92\%E5\%8C\%96\%E5\%BC $\% 82 \%$ E5\%8C\%96/2291724

[6] https://baike.baidu.com/item/\%E5\%BD\%92\%E5\%8C\%96\%E5\%BC $\% 82 \% \mathrm{E} 5 \% 8 \mathrm{C} \% 96 / 2291724$

[7] Schuttleworth \& Cowie. Dictionary of translation studies. Manchester : STJE Rome,1997.

[8] Lawrence, Venuti. The Translator's Invisibility. London \& New York Routledge, 1995 